\title{
Crítica à razão gestionária na educação: \\ o ponto de vista do trabalho
}

WANDERSON FERREIRA ALVES

Universidade Federal de Goiás,

Goiânia, GO, Brasil

\section{INTRODUÇÃO}

Nas páginas iniciais de instigante artigo sobre as práticas avaliativas em marcha no mundo do trabalho atual, Marie-Anne Dujarier conferiu bem a dimensão da passagem dos modelos de avaliação em voga no setor privado para o setor público. Em suas palavras, trata-se de

Sistemas contemporâneos que anunciam fazer a avaliação do trabalho e no trabalho. Eles foram desenvolvidos progressivamente, desde um quarto de século, na maior parte das organizações privadas, em seguida nas públicas. Professores, agentes do serviço público de emprego, policiais, puericultoras, jardineiros, trabalhadores sanitários e sociais, juízes, pesquisadores e mesmo ministros são agora "avaliados" com os mesmos métodos que os vendedores, empregados, gerentes, técnicos e operários da indústria ou do serviço privado. (Dujarier, 2010, p. $135-136)^{1}$

$\mathrm{Na}$ área da educação, sabemos bem o que nos conta Dujarier. Para além do juridicamente já disposto sobre a avaliação à qual se deve submeter todo funcionário público ou da avaliação em larga escala - em parte implicada no que será tratado

1 Todas as traduções efetuadas no presente artigo são livres e de minha inteira responsabilidade. 
aqui - das escolas de uma rede de ensino, ganha corpo na área da educação a proposição de que é pertinente a avaliação direta do trabalho docente, mensurando-se seu desempenho.

O paralelismo com certas práticas do setor privado não é coincidência e poderemos acompanhar ao longo do texto como isso se apresenta - no fundo, esse fato diz respeito à tensa relação entre gestão e trabalho. Mas aqui não nos contentaremos apenas em sublinhar o paralelismo mencionado, sendo mais amplo o objetivo: trataremos de problematizar as ambições da gestão ${ }^{2}$ em relação ao trabalho humano e algumas das iniciativas que, no âmbito da educação escolar, atualmente buscam governá-lo e dimensioná-lo, indagando especialmente a racionalidade gestionária que as orienta. Para tal empreitada, serão mobilizadas as contribuiçõos de estudos na área da educação e também das disciplinas que têm o trabalho como objeto de estudo, especialmente as contribuições da ergonomia da atividade, ${ }^{3}$ disciplina que elabora uma análise muito fina do que concretamente fazem os homens e mulheres no trabalho; por isso, fala-se em buscar o ponto de vista do trabalho ou, caso se queira, buscar o ponto de vista da atividade humana de trabalho.

No item a seguir, partiremos de uma situação concreta, o caso da rede pública estadual de ensino do estado de São Paulo. Desenvolvendo teoricamente a questão, refletiremos sobre o trânsito das ferramentas de gestão do setor privado

2 A gestão pode ser compreendida, em sentido lato, como incumbências de coordenação, de tomadas de decisão organizacionais - estratégicas ou operacionais - e uso da atividade de trabalho de coletivos de homens e mulheres, tendo em vista determinado fim, como, por exemplo, o atendimento em um hospital público ou ganho de natureza econômica para a empresa privada. No texto, quando nos referirmos à gestão, é essa a perspectiva que de modo geral teremos em mente. Mas é oportuno, desde já, firmar outra perspectiva em torno do assunto, no que seguimos nas reflexões de Yves Schwartz. Para o autor, o realizar do trabalho comporta sempre - em diferentes níveis uma dimensão de gestão: trabalhar compreende uma dialética entre o uso de si por outros e o uso de si por si; o primeiro marcando o enquadramento político-econômico e jurídico da subordinação no salariado e também a relação com as hierarquias e com os colegas de ofício; o segundo sublinha que, não sendo pura execução do prescrito, trabalhar demanda o realizar de arbitragens, agir no hic et nunc, efetuar microescolhas (por vezes em desacordo com o que foi prescrito) essenciais para que se realize o que precisa ser realizado, como bem demonstram os ergonomistas. Nesse sentido bastante preciso, podemos dizer que trabalhar é gerir, na verdade, uma confrontação de gestões (Schwartz, 2000).

3 A ergonomia é uma disciplina que mobiliza conhecimentos de diversas áreas (fisiologia, medicina, psicologia do trabalho, sociologia do trabalho etc.) tendo em vista conhecer e transformar o trabalho, considerando a eficácia, o conforto e a saúde do trabalhador. Grosso modo, existem duas grandes vertentes na ergonomia: uma de linhagem anglo-saxônica, de corte positivista e cujo interesse é a adaptação do homem ao trabalho, tendo como foco o equipamento; outra vertente é a da ergonomia que se constituiu inicialmente na França, apoiada na noção de atividade e cujo interesse é a adaptação do trabalho ao homem, tendo como foco o trabalho. Neste estudo, adotamos a perspectiva da ergonomia de base francesa. Sobre os fundamentos da ergonomia, ver os vários textos na obra dirigida por Daniellou (2004); sobre as contribuições da ergonomia e da ergologia para o estudo do trabalho docente, ver Alves (2010). 
para o público e sobre a efetividade de tais ferramentas no próprio contexto do setor privado. Abordaremos ainda as contradições e limites desses modelos e ferramentas de gestão - que são também as contradições e limites da própria gestão - diante da complexidade do trabalho humano, para retomar uma antiga expressão de Georges Friedmann.

\section{O CASO DA REDE PÚBLICA ESTADUAL DE ENSINO PAULISTA}

Se alguém desejar o exemplo mais acabado da racionalidade gestionária na área da educação escolar brasileira, possivelmente este seja encontrado na rede pública de ensino do estado de São Paulo. O começo dessa história pode ser situado nos anos de 1990, quando a educação em São Paulo presenciou um conjunto de ações de gestão tendo em vista alterar o perfil das escolas e do ensino oferecido - o contexto coincide com a Reforma do Estado e o New Public Management,$-{ }^{4}$ com os quais o governo paulista ensaiava uma nova modelação da educação escolar.

Estavam em marcha técnicas de gestão e racionalidade econômica na educação paulista. Desejadas no âmbito da política, constituídas e declinadas na esfera da gestão e vivenciadas pelo professorado paulista, essas questões foram objeto de estudos e pesquisas ${ }^{5}$ que destacaram uma inabalável crença no poder da gestão de modelar as escolas e o trabalho dos professores, sublinharam um modelo de gestão no qual as deliberações eram verticais e unilaterais - em cujo interior, veremos mais adiante, podemos localizar a gestão funcionando pela ênfase na prescrição da tarefa. ${ }^{6}$

Os professores paulistas não experienciaram "qualquer reforma", mas algo bastante substantivo. Em pesquisa sobre as políticas educacionais paulistas, Maria José da Silva Fernandes sintetiza bem o que ocorreu: "Em nenhuma outra ocasião, a educação paulista conhecera um pacote de medidas tão articuladas e capazes de alterar substancialmente as escolas como o que se apresentou naquele momento" (Fernandes, 2010, p. 77).

4 No plano internacional, os anos de 1980 e 1990 marcaram o momento da hegemonia neoliberal e, no campo da administração pública, ganhava força o movimento que ficou conhecido como New Public Management, que se inspirava no modelo de gestão do setor privado para pensar a gestão pública. Retornaremos ao assunto na sequência do texto.

5 A política e a gestão da educação paulista foram estudadas por diversos pesquisadores, podendo ser citados aqui os trabalhos realizados por Souza (2000), Fernandes (2010) e Minhoto e Penna (2011).

6 Utilizamos aqui os conceitos ergonômicos de trabalho prescrito, trabalho real e atividade. O trabalho prescrito - esfera da tarefa - compreende o que deve ser realizado e o que deve ser observado para essa realização. $O$ trabalho real é o efetivamente realizado dentro de uma situação concreta. Trata-se de uma distinção fundamental e uma constatação: há sempre uma decalagem entre trabalho prescrito e trabalho real. A atividade compreende a presença humana na mediação do prescrito ao real, aquilo que o trabalhador faz, engaja e mobiliza (inteligência, corpo, memória, interfaces com o coletivo etc.) no processo de realização da tarefa. 
Em que pese o conjunto de ações posto em movimento, a qualidade da educação naquela rede de ensino ao final da primeira década do século XXI continuava bastante aquém do esperado. A saída vislumbrada, contudo, não foi o abandono do caminho que durante anos - na verdade, mais de uma década - vinha sendo trilhado, mas a continuidade e o aprofundamento daquele mesmo gênero de decisões.

Ocorre que, tendo como ponto de partida o diagnóstico de que seria preciso "motivar" o professor, interessados também em conter o importante absenteísmo docente e imbuídos de um espírito desejoso de incorporar novos modelos e ferramentas de gestão do setor privado à administração pública, os gestores da secretaria da educação paulista tomaram duas decisões com incidência direta sobre o trabalho docente: carreira meritocrática e pagamento por desempenho. ${ }^{7}$ Em tais medidas, podemos dizer que o trabalho docente é literalmente dimensionado: seu contorno é tido como perfeitamente delimitável, sua substância é concebida como mensurável e seus resultados entendidos como quantificáveis.

Do modo como são apresentadas, tais medidas se mostram como racionais e de bom senso, acreditando-se que a remuneração diferenciada estimula o engajamento docente e que a premiação por mérito é critério de justiça. Assumidos como mecanismos eficazes no setor privado, a corrida pelo mérito e o pagamento diferenciado por desempenho se consubstanciaram em práticas integradas à educação pública paulista.

A rigor, trata-se de formas de governo do trabalho - este último é especificado: por meio da prescrição da tarefa via guias curriculares, projetos que chegam prontos às escolas etc.; dimensionado: por meio de ferramentas que objetivam quantificar o trabalho do professor e o trabalho realizado pelo conjunto da escola, tornando-os mensuráveis (percentual de aprovação, número de projetos desenvolvidos, índices, metas, resultados da unidade escolar nas avaliações do Sistema de Avaliação do Rendimento Escolar no Estado de São Paulo [SARESP] etc.); conduzido: por meio de incitação pecuniária, classificação das escolas, exposição dos resultados de avaliações etc. Nesse horizonte, o trabalho, no caso o trabalho docente, se apresentaria - e isso no sentido literal do termo - como objeto da gestão, respondendo a seu interesse instrumental e modelado a partir de fora.

7 Pagamento por desempenho - por iniciativa dos gestores no âmbito da Secretaria da Educação do Estado de São Paulo, a lei complementar n. 1.078/2008 instituiu um sistema de bonificação por resultados. De modo resumido, podemos dizer que este consiste em remuneração pecuniária paga aos trabalhadores em educação de uma unidade escolar que, após avaliação externa, tenha progredido nos indicadores fixados pela Secretaria. Carreira meritocrática - além do pagamento pelo desempenho positivo dos docentes, a Secretaria da Educação introduziu uma modificação importante no que se refere à carreira do magistério: a promoção na carreira baseada no mérito. A lei complementar n. 1.097, regulamentada pelo decreto n. 55.217/2009, estabeleceu que os docentes seriam promovidos ao patamar seguinte de sua carreira profissional caso se submetessem a processo de avaliação (prova teórica de conhecimentos específicos) promovido pela Secretaria da Educação. Interessante estudo sobre a questão pode ser visto em Minhoto e Penna (2011). 
Resumidamente aqui relatado, o caso da educação escolar pública no estado de São Paulo interessa muito quando, na área da educação, trata-se de compreender o alcance da racionalidade gestionária e de sua relação (por vezes bastante conflituosa) com o trabalho humano. É justamente sobre esse ponto que desejamos refletir, pois é preciso tentar entender o que permitiu a constituição das iniciativas anteriormente assinaladas, o que as endossa e quais são suas contradições.

Seria possível indagar: Qual horizonte político-ideológico lançou as bases para tais iniciativas na administração pública? Os modelos e ferramentas de gestão do setor privado podem ser classificados, sem mais, como exitosos ou existem graves contradições - por vezes nefastas para a própria empresa - dificultando suas práticas? Se colocar o trabalho em números é algo imprescindível para a gestão, esse mesmo exercício não importaria reduções problemáticas? Qual o alcance das atuais práticas de gestão - e, especialmente, da gestão da educação - diante da complexidade do trabalho humano? Tais indagações balizam as reflexões presentes nas próximas seções do texto.

\section{ADMINISTRAÇÃO PÚBLICA E ESPÍRITO DA EMPRESA PRIVADA}

O que permite a um secretário ou secretária da Educação argumentar, sem mais, que na administração pública é preciso "premiar o mérito"? O que endossa a instituição de uma lógica de avaliação do trabalho - como na legislação que institui a bonificação de resultados para os professores paulistas - cuja linguagem navega por termos como metas, indices, desempenho, apuração de resultados?

Podemos especular o que referenda tais práticas. Certamente poderíamos considerar na análise o movimento de racionalização (Max Weber) no seio de uma modernidade calculadora ou, apelando para um difuso espírito liberal, poderíamos considerar, no quadro histórico-político brasileiro, a possível existência de interesses político-partidários. Mas, mesmo que em parte ligados aos aspectos anteriores, existem certos desenvolvimentos no âmbito da educação e das políticas, do ponto de vista dos pressupostos que balizam a relação entre gestão e Estado, que ganharam corpo e substância nas últimas décadas e que nos ajudam a entender bem por quais vias seguem secretários e secretárias da Educação quando anunciam suas medidas modernizadoras.

A racionalidade gestionária presente na educação torna-se inteligível pela compreensão de alguns dos pressupostos que sustentam certas ações no âmbito da administração pública e lhe conferem legitimidade. ${ }^{8}$ Um dos aspectos que compõem

8 Há vários desenvolvimentos particulares ao âmbito da educação que poderiam ser destacados por contribuírem com a sedimentação de políticas e práticas gestionárias, como a corrente de base econômica e pragmática, que parece ter convertido seus pressupostos em senso comum, denominada escolas eficazes, internacionalmente conhecida por school effectiveness. A esse respeito, ver Mons (2009) e Normand (2006). No entanto, nos limites deste espaço e dos propósitos do texto, iremos nos deter em aspectos mais abrangentes que fomentam a elaboração de políticas e modos de gestão. 
o fundo pelo qual certas ferramentas de gestão ganham movimento pode ser situado no âmbito da teoria do capital humano, no sentido de que esta, ao identificar uma estreita relação entre desenvolvimento econômico e educação, compreende também que isso não se faz a qualquer preço e demanda, sob os auspícios da racionalidade econômica, medidas que contabilizem, de um lado, os meios empregados (denominados de fatores de produção) e, de outro, os resultados obtidos (identificados como sendo os produtos).

É possível pensar dessa forma o serviço público? Na própria área da gestão, essa proposição é discutível (Dejellal; Gallouj, 2007). Seja como for, os economistas precisam ter informações sobre os inputs e outputs do sistema, para assim "fazer girar seus modelos estatísticos e pôr em evidência as configurações institucionais eficazes"; nesse horizonte, "tomam um novo olhar sobre o sistema educativo apoiados por uma regulação por resultados" (Mons, 2009, p. 106). A teoria do capital humano encontra nesse ponto sua faceta operacional - o fato será retomado mais adiante, mas é oportuno notar que já aqui o trabalho humano é abstraído e somente existe na forma de "fator de produção" e "produtor de resultados". Outro aspecto que constitui a racionalidade gestionária na esfera pública - e que não pode deixar de ser mencionado - é a perspectiva aberta com o New Public Management.

$\mathrm{Na}$ esteira da vaga neoliberal, a partir dos anos 1970, a administração pública foi questionada quanto à sua eficiência e ações direcionadas à sua renovação foram postas em marcha. Nascida nos Estados Unidos, uma corrente da administração ganhou expressão internacional ao propor um sistema de racionalização das ações do estado, prometendo melhor relação custo-eficácia, utilizando, para isso, modelos e ferramentas de gestão do setor privado. Trata-se do movimento conhecido por Neww Public Management, ou Nova Gestão Pública. ${ }^{9}$

Mons (2009) apresenta um resumo com alguns dos princípios desses novos modos de conceber a gestão pública. Esses partiriam dos seguintes pressupostos: a) a produção de serviços públicos é mensurável; b) sua mensurabilidade se constitui graças a ferramentas específicas cuja validade deve ser cientificamente testada; c) os servidores públicos devem prestar contas de suas ações aos gestores e/ou aos cidadãos; d) a organização pública deve ser regulada por resultados e não mais por meios procedimentais orientados com base na disponibilização de recursos. $\mathrm{O}$ quadro a seguir (Quadro 1) apresenta os pressupostos anteriormente assinalados e seus resultantes operacionais. O leitor e a leitora perceberão como, no contexto da Reforma do Estado, a gestão da educação no Brasil, desde a década de 1990, seguiu bem a cartilha.

9 Para conhecer como tal ideário foi vivamente acolhido no Brasil, ver Pacheco (1998); para uma visão crítica, ver Bezes (2005). 
Quadro 1 - Principais orientações do Nerw Public Management

\begin{tabular}{|l|l|l|}
\hline \multicolumn{1}{|c|}{ Princípios } & \multicolumn{1}{|c|}{ Objetivos } & \multicolumn{1}{c|}{ Aç̃̃es típicas } \\
\hline $\begin{array}{l}\text { Reorganizar as unidades } \\
\text { operacionais por produto }\end{array}$ & $\begin{array}{l}\text { Separar regulação e concepção } \\
\text { de sua realização }\end{array}$ & $\begin{array}{l}\text { Criação de agências, } \\
\text { contratualização }\end{array}$ \\
\hline $\begin{array}{l}\text { Reforçar a concorrência } \\
\text { interna e externa }\end{array}$ & $\begin{array}{l}\text { Baixar custos e melhorar } \\
\text { padrões pela concorrência }\end{array}$ & $\begin{array}{l}\text { Instigar a oferta, benchmarking, } \\
\text { contratualização }\end{array}$ \\
\hline $\begin{array}{l}\text { Responsabilizar os gestores } \\
\text { (autonomia e accountability) }\end{array}$ & $\begin{array}{l}\text { Evitar a difusão do poder e } \\
\text { clarificar responsabilidades }\end{array}$ & Autonomia do gestor de projeto \\
\hline $\begin{array}{l}\text { Assegurar maior disciplina } \\
\text { orçamentária }\end{array}$ & $\begin{array}{l}\text { Redução de despesas públicas, } \\
\text { fazer melhor com menos }\end{array}$ & $\begin{array}{l}\text { Teto de despesas, redução de } \\
\text { efetivos, trabalho por objetivos }\end{array}$ \\
\hline $\begin{array}{l}\text { Valorizar instrumentos de gestão } \\
\text { exitosos no setor privado }\end{array}$ & $\begin{array}{l}\text { Transformar a estrutura } \\
\text { das incitações e controle }\end{array}$ & $\begin{array}{l}\text { Ferramentas de gestão } \\
\text { (contabilidade analítica, controle } \\
\text { de gestão), contratualização }\end{array}$ \\
\hline $\begin{array}{l}\text { Tornar explícitos, formais } \\
\text { e verificáveis as normas } \\
\text { e desempenhos }\end{array}$ & $\begin{array}{l}\text { Reforçar a responsabilidade } \\
\text { determinando precisamente } \\
\text { os objetivos }\end{array}$ & $\begin{array}{l}\text { Indicadores quantitativos } \\
\text { de gestão e de qualidade } \\
\text { para avaliar os resultados }\end{array}$ \\
\hline $\begin{array}{l}\text { Centrar na avaliação } \\
\text { de resultados }\end{array}$ & Instituir a obrigação de resultados & $\begin{array}{l}\text { Recursos e remunerações } \\
\text { ligados a desempenhos, prêmios } \\
\text { conforme os resultados }\end{array}$ \\
\hline
\end{tabular}

Fonte: Mons, 2009, p. 104.

Elaboração do autor.

Acompanhando o Quadro 1, podemos identificar como a organização do trabalho é projetada: separação entre regulação e concep̧̧ão de sua realização; como a noção de concorrência é introduzida supondo aumento de eficácia/eficiência: baixar custos e melhorar padröes pela concorrência; como autonomia e responsabilização vão sendo incessantemente conjugadas: autonomia e accountability. Tudo isso - destaque importante - exaltando o modelo de gestão do mundo dos negócios: valorizar instrumentos de gestão exitosos no setor privado, acrescendo sistemas de gestão por objetivos, sistemas de aferição de resultados quantificáveis (o que resultará em uma profusão de indicadores) e remuneração ligada ao desempenho. Enfim, têm-se uma verdadeira caixa de ferramentas para que os agentes interessados possam realizar a reengenharia da administração pública (Bruno, 2008).

Para os partidários de tal empreendimento, tudo isso significa modernizar a gestão pública. Trata-se, em resumo, da aproximação entre administração pública e formas de gestão contemporâneas no setor privado, este último compreendido como o modelo de êxito a ser perseguido. Um aberto elogio ao seu espírito, suas ferramentas de gestão, de incitação e de controle.

Nesse ponto, talvez seja pertinente fazermos uma pausa e conhecer um pouco do que atualmente vem acontecendo nas situações concretas de trabalho das empresas e instituições contemporâneas perpassadas por esse novo management. Como está o trabalho visto a partir de baixo? 


\section{EXPERIÊNCIAS EXITOSAS NO MUNDO DOS NEGÓCIOS?}

A France Télécom, empresa francesa do setor de serviços de telecomunicação, viu-se às voltas com uma gravíssima questão: o suicídio de vários de seus funcionários. Desde os anos 2000, foram registrados na France Télécom mais de quarenta suicídios, o que levou o repórter de um jornal francês a fazer ao presidente da referida companhia uma desconcertante indagação: Por que esses assalariados, bem pagos e ao abrigo do desemprego, chegavam a ponto de suicidarem-se em seu local de trabalho? A resposta da direção, naquele instante e por muito tempo, foi a de imputar ao assalariado certa fragilidade pessoal e dificuldade de adaptação aos novos tempos da empresa - privatizada na segunda metade dos anos 1990 e exposta a forte processo de reestruturação.

O caso da France Télécom foi bastante midiatizado e recebeu também a atenção do meio acadêmico (Clot, 2010; Zarifian, 2009). Entre esses estudos, um ponto em comum: o entendimento de que o processo de reestruturação da empresa e as novas formas de gestão, combinando incitação e controle, degradaram as situações de trabalho e desenharam um quadro em que, no limite, o trabalho se tornou, por vezes, insuportável.

Conforme podemos depreender desses estudos, vários elementos se combinaram naquela situação: o forte processo de reorganização da empresa foi, de certo modo, eficaz em produzir a mudança de seus assalariados. Zarifian (2009) observa que, em virtude de tais ações gestionárias, em um curto período, entre 1996 e 2006, aqueles trabalhadores já não eram os mesmos em suas demandas, em seus modos de argumentar e pensar, nem no que faziam concretamente; no entanto, essa forte mudança significou também o apagamento dos modos de fazer coletivamente constituídos pelos trabalhadores, modos de fazer visíveis, por exemplo, quando um trabalhador diz "aqui a gente faz assim". Sem esse reservatório que acumula a história social da profissão, aponta Yves Clot, o trabalhador é deixado diante de si mesmo em face dos imponderáveis cotidianamente enfrentados nas situações de trabalho.

Contudo - e aqui está o cerne da questão -, se, por um lado, tais ações da gestão, que visavam modernizar a empresa e torná-la mais competitiva, esfacelaram o coletivo e tornaram o exercício laboral cada vez mais resultante de um desempenho individual, por outro, a empresa continuava a acrescer novas formas de management e pôr em marcha mecanismos do tipo fixação de objetivos/controle de resultados. Entre os dois termos, é oportuno notar, a atividade de trabalho desaparece, ou seja, apaga-se o que diz respeito ao engajamento do trabalhador, às dificuldades na realização da tarefa, aos imprevistos que precisam ser geridos, à inteligência empregada, ao que se arriscou, enfim, ao que aquilo efetivamente demandou para ser realizado. $\mathrm{O}$ que conta são os resultados e as consignas iniciais. É nesse horizonte que entra em jogo a relação entre trabalho e saúde.

Pesquisadores notaram o efeito deletério para a saúde do trabalhador a sua imersão em uma situação laboral em que se tem consciência do que é o trabalho bem-feito, mas não lhe são oferecidos os meios para fazê-lo ou a própria empresa 
deliberadamente não o deseja. No caso da France Télécom, a qualidade do trabalho a ser realizado parecia conflitar com a concepção de qualidade de parte de seus assalariados, ${ }^{10}$ visando estes últimos a clientes reais com suas demandas e características específicas, que precisavam ser adequadamente atendidas. Em contrapartida, do lado da empresa esse cliente era, de certo modo, uma ficção: por trás de uma cega corrida pelo alcance de metas e observância de indicadores, o cliente real desapareceu e a qualidade foi suprimida pela quantidade.

$\mathrm{Na}$ prática diária dos trabalhadores da empresa, como trabalhar não é simplesmente executar, os conflitos de valores se estabeleciam. Na ocasião da repercussão de mais um suicídio na France Télécom, Yves Clot e Philippe Zarifian escreviam em uma edição do Le Monde que o ponto cego naquele sistema de avaliação de desempenho era a crença de poder passar ao largo do trabalho real; assim, as ações da gestão obscureciam o trabalho e as condições de seu exercício, mas este continuava lá e cobrava seus efeitos. Observando que o próprio governo francês opinou a respeito - chega de "religião de números", disse o chefe de Estado -, os referidos autores assinalam, não sem ironia, que, em relação aos números, mais laicidade teria feito melhor à France Télécom (Clot; Zarifian, 2009).

O que foi aqui sumariamente narrado sobre a France Télécom compreende uma situação-limite. Todavia, as questões que envolvem os sistemas de gestão na atualidade não se exprimem em uma forma, mas em formas, como no aumento de casos de Doenças Osteomusculares Relacionadas ao Trabalho (DORT) e no fenômeno da intensificação do trabalho.

Em relação a esses fatos, um conjunto consistente de estudos e pesquisas empíricas evidencia, no seio do mundo do trabalho atual, uma série de contradições na relação entre a gestão e o trabalho que depõe contra a qualidade do trabalho, contra a saúde dos trabalhadores e mesmo, em médio prazo, contra os próprios objetivos almejados pela instituição ou empresa (Clot, 2010; Daniellou, 2010; Hubault, 2009; Théry, 2010).

Ocorre que uma combinação de decisões organizacionais, de decisões técnicas, decisões em relação à política de pessoal, em relação aos novos métodos de gestão e de acompanhamento do desempenho do trabalhador vem produzindo uma situação em que o trabalho agrega outros níveis de penibilidade. Esse é o quadro que constitui o fenômeno da intensificação do trabalho no mundo atual.

Como destaca Bernard Dugué (2010, p. 107), o quadro é paradoxal: "quando se pergunta ao trabalhador sobre a evolução de seu trabalho, ouve-se frequentemente como resposta: 'existem melhorias, mas é mais e mais duro'. François Daniellou, ergonomista com larga experiência no estudo das situações de trabalho, baseado nos dados de um de seus estudos relata o caso dos trabalhadores de soldagem em uma indústria que seguia bem as consignas modernizantes. Vejamos o que ele diz.

10 Como a empresa havia sido privatizada, parte de seus funcionários portava certos valores (o valor serviço público) que colidiam com o novo espírito da empresa. 
Após estar equipado, conta Daniellou (2010), um soldador dirige-se ao seu posto de trabalho. Antes, no corredor, encontra-se com o supervisor, que o chama à atenção por seu atraso e lhe diz que a qualidade dos tubos produzidos na jornada anterior não estava adequada aos padrões. $\mathrm{Na}$ empresa, o posto desse trabalhador está organizado em um sistema cujo arranjo tem a forma de U.

Tal sistema é atualmente recorrente em vários setores e ramos econômicos, como na indústria do vestuário, e sua proposição é contribuir para a melhor organização do trabalho e facilitação da regulação da produção pelos trabalhadores. No contexto da mencionada empresa, o referido sistema oferece pouco espaço para deslocamento, as passagens entre as máquinas são parcialmente bloqueadas pelas peças e o barulho atrapalha quando se precisa advertir para algum problema ou mesmo quando se precisa de alguma informação com os colegas.

A produção está atrasada, continua Daniellou (2010), mas, enfim, as peças se sucedem no recipiente de resfriamento; o procedimento assegura o resfriamento da peça, ao passo que captores aspiram a fumaça resultante das soldagens. Naquele dia, como de hábito, o supervisor faz pressão para que o processo siga mais rápido: é preciso recuperar o atraso. $\mathrm{O}$ tempo de resfriamento não é respeitado, a fumaça com odor característico de metal quente toma a atmosfera e todos a respiram.

Fazendo uma espécie de volta no tempo, Daniellou explica que antes não era desse modo que as coisas ocorriam: antes da implantação do Hoshin - método japonês que consiste em concentrar os esforços da empresa em objetivos amplos e direcionados à melhoria contínua dos processos -, a soldagem era realizada em um ateliê próprio e com mecanismos especiais para extração do ar; em seguida, as peças seguiam em diferentes linhas, o que separava e protegia da fumaça os encarregados da montagem. Mas, com a chegada do Hoshin, os vários setores da empresa foram instados a contribuir para as mudanças, já integradas a um objetivo maior: diminuir o deslocamento inútil de peças, reagrupando as operações por produto.

Esses assalariados foram, então, associados à busca por ganho de espaço, não lhes tendo sido perguntado sobre os critérios, mas somente sobre os meios de se atingir o objetivo previamente formulado, uma vez que o bom para todos já estava definido. E quanto ao resultado? Cada tipo de peça passa a ser produzido em uma linha em U, com a soldagem incluída. A linha em U possibilita quatro trabalhadores para sete máquinas, em vez de um para uma única máquina. $\mathrm{O}$ posto de soldagem está situado no meio da linha de montagem. Agora não há mais a necessidade de se deslocar, o que, em todo caso, ficaria mesmo difícil, pois as passagens entre as máquinas estão obstruídas por peças aguardando para serem refeitas. A produção aumenta em algo de 30\% e o número de trabalhadores está em baixa; a qualidade, porém, deteriora-se: as peças são montadas ainda quentes e se deformam. Quanto àqueles trabalhadores que foram associados à reconcepção da linha, estes já não têm mais ânimo para indicar os problemas que aqueles novos arranjos fizeram emergir. Também não era previsto que o supervisor aumentasse a frequência de suas visitas ao setor, nem que não haveria tempo para resfriar as peças, muito menos que haveria aquela quantidade de peças para serem, justamente, refeitas! 
Como podemos perceber, as "miragens do management", para usar a expressão de Dugué (2010), diluem-se quando se acompanha de perto o que concretamente fazem os homens e mulheres no trabalho. Assim como vimos no setor terciário, o caso da France Télécom, vimos também o caso de uma indústria com os trabalhadores na área de soldagem. E poderíamos seguir acrescentando outros casos a uma lista que seria um tanto longa. ${ }^{11}$ Enfim, depois de acompanharmos tudo isso, parece importante compreendermos com base em quê, exatamente, as empresas tomam suas decisões, pois, se é verdade que ao final das contas a produção "sai", nem sempre isso pode ser creditado a uma especial desenvoltura dos managers. Dirigentes de empresas ou instituições que nos desculpem pela impertinência da indagação, mas a pergunta não pode ser outra: o que a gestão realmente conhece sobre o trabalho que precisa gerir?

\section{TRABALHO: CADA VEZ MAIS CONHECIDO E, PARADOXALMENTE, DESCONHECIDO PELA GESTÃO}

Uma imagem bastante sugestiva para se pensar o que comumente ocorre no interior de empresas privadas - ou empresas/instituições públicas - é oferecida por Daniellou (2010). Ele sugere que aspectos-chave na compreensão do funcionamento da empresa podem ser identificados em dois níveis: o alto (nível da direção geral) e o baixo (departamentos nos quais se produzem os bens ou serviços). Várias dimensões estão reunidas nesses domínios: a qualidade, os custos, os prazos, os recursos humanos (termo esse revelador de um modo de conceber o ser humano nas empresas), os materiais, a segurança, os impactos ambientais.

Entre o alto e o baixo, essas dimensões da vida da empresa são tratadas por serviços especializados: com base nas grandes orientações da direção, o serviço de qualidade produz diretrizes para a qualidade, o serviço de segurança produz consignas de segurança, a direção de recursos humanos orienta a chegada dos jovens etc. No nível da produção, a atividade das chefias e operadores precisa integrar as diretivas gerais e produzir o que se tem para produzir com os recursos disponíveis. Daniellou (2010, p. 89) observa que "nem um nem outro chega a fazer tudo perfeitamente, mas a produção sai", e acrescenta: "o que foi preciso fazer para se chegar a ela, o que aquilo custou, o estado em que estão as pessoas, isso é outra coisa, da qual a direção geral nada sabe, pois as informações que lhe chegam sobem pelos mesmos canais especializados que as fazem descer" (idem, ibidem).

Mas, em que pese tal situação descrita, o serviço responsável pela qualidade atesta; tudo certo: 93,6\%; as informações sobre os prazos seguem via setor comercial; tudo vai bem: 97,6\%; taxa de frequência de acidentes: quase estável, mas com ligeiro aumento de $0,2 \%$; do lado da direção de recursos humanos, nada a assinalar

11 Uma pitoresca relação dessas "estratégias absurdas", como sugere o título da obra, pode ser vista em Beauvallet (2010). 
e, ademais, não há greves. "Visto do avião, funciona bem”, diz com ironia Daniellou (idem, p. 90). E complementa: no interior das grandes empresas, o conhecimento da realidade que a direção geral possui e aquele dos assalariados que atuam no terreno não se encontram praticamente nunca: "a direção pilota a empresa com sua 'visão', um jornal sobre o para-brisa e um painel de controle transbordando indicadores parciais" (idem, ibidem).

Tudo bem; alguém pode argumentar que a imagem caricatural trazida por Daniellou possui algum exagero, mas, infelizmente, ela não está em descompasso com os modos de proceder que perpassam muitas empresas e instituições. Infelizmente, porque, pela posição nas relações sociais de produção, são os trabalhadores e trabalhadoras que assumem o prejuízo pelas decisões efetuadas por diretores e consultores. São suas vidas que estão em jogo, sua profissão, sua saúde e seu futuro. Na verdade, o que Daniellou evidencia é a profunda dificuldade de os gestores lidarem com o trabalho humano nas situações concretas. Nesse âmbito, decisões são tomadas com base em um conhecimento muito parcial do que realmente é realizado individual e coletivamente por homens e mulheres no trabalho. Vista de perto, a gestão revela seus pontos cegos.

Bernard Dugué oferece um bom exemplo do modo como, não raramente, se procede no alto das organizações. Ele narra o caso de um gabinete de consultoria que desenvolvia suas atividades no setor bancário. O objetivo da consultoria era atuar sobre a eficácia dos serviços e das agências.

Procede-se à separação da atividade de cada agente em tarefas elementares (acolhimento do cliente, telefone, tratamento desta ou daquela operação, tratamento de tal tipo de dossiê, análise das notas de serviço etc.). A totalidade dessas tarefas elementares é tida como representando, grosso modo, a jornada de trabalho dos agentes. Soma-se o tempo passado em cada tarefa por todos os agentes do serviço ou das agências e converte-se esse tempo em postos ETP (equivalente tempo pleno). Nós vamos, por exemplo, encontrar que, sobre a totalidade das agências, a atividade telefônica corresponde a 16,3 ETP, uma outra a 8,5 ETP etc. [...] Observa-se em seguida sobre quais tarefas se pode ganhar tempo - e, então, os ETPs - para, em seguida, calcular o sobre-efetivo potencial da empresa. [...] Atrás da perspectiva utilizada, encontraremos finalmente aquela mesma ideia de que o trabalho se deixa facilmente quantificar, prescrever, fechar dentro dos procedimentos... para quase se chegar a suprimir as variabilidades. $O$ tempo de preparação e conversa com os colegas, o tempo para si, o tempo de substituição de alguém ausente momentaneamente, o tempo consagrado à gestão de incidentes ou ao tratamento de um dossiê atípico não são levados em conta nesses cálculos. Não se diz como se vai concretizar a economia de meio ETP na atividade telefônica de todas as agências: cada um vai telefonar menos tempo? Vai-se telefonar menos em certas agências? Vai-se interromper os telefonemas a partir de um certo momento? Apesar do absurdo dessas abordagens do trabalho, os dirigentes se obstinam. (Dugué, 2010, p.114) 
O que Dugué (2010) nos mostra é uma forma de proceder que faz completa abstração do trabalho concreto, por isso as variabilidades ${ }^{12}$ não são consideradas: se é preciso algum tempo para si mesmo, se certos encaminhamentos demandam o diálogo com os colegas, se é necessário tempo para tratar o dossiê atípico, se há pequenos incidentes que precisam ser resolvidos na preparação... Nada disso entra no cálculo. $\mathrm{O}$ contexto que constitui a história daquele departamento e grupo de trabalhadores não é considerado. Quantas supressões de postos de trabalho não são feitas assim? Quantas ações de reorganização de empresas e instituições são desenhadas por lógicas mais ou menos semelhantes e terminam por dificultar seriamente o que as pessoas fazem? Como podemos depreender, certas ações são postas em marcha em uma terra incógnita.

$\mathrm{Na}$ educação, sabemos bem o peso de tais formas de proceder, visíveis explicitamente quando, por exemplo, por ocasião de reformas curriculares ou implantação de um novo modelo de organização de uma rede de ensino. Se considerarmos o ensino como trabalho, podemos dizer que decisões tão comuns como essas são tomadas por vezes na completa ignorância de seus efeitos concretos sobre o trabalho dos professores.

As más decisões descritas nos parágrafos anteriores não consistem em uma idiossincrasia deste ou daquele responsável pela gestão. Há bem mais que isso. De um lado, veremos mais adiante, podemos apontar que a relação entre a gestão e o trabalho tem qualquer coisa de contraditório que não se pode simplesmente solucionar, mas, antes, enfrentar e desenvolver; de outro, o horizonte que se abre com a crescente busca por conduzir a gestão com base em indicadores - e aqui podemos compreender o sentido dos dispositivos que objetivam realizar a avaliação do e no trabalho - arrisca-se a constituir uma lógica em que aquilo que concretamente fazem homens e mulheres no trabalho torna-se cada vez mais distante da gestão, o que não resta sem consequências. Vejamos com mais detalhes o que acaba de ser apontado.

\section{INELIMINÁVEIS TENSÕES}

Diante da totalidade - humana, técnica, socioeconômica - que compreende a vida de uma empresa ou de uma instituição, a ação da gestão envolve sempre um

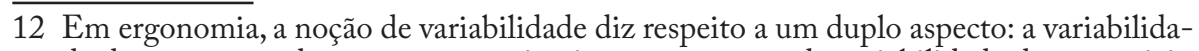
de do contexto e das pessoas; no primeiro caso, trata-se da variabilidade dos materiais, das ferramentas, das máquinas, dos prazos de um fornecedor, da realização de uma tarefa etc.; no segundo, trata-se da variabilidade interindividual (em relação às outras, cada pessoa possui uma altura, um peso, uma boa visão ou não, como também tem uma história, experiências profissionais, uma formação etc.) e da variabilidade intraindividual (cada indivíduo possui características singulares: o corpo humano obedece a ritmos biológicos que fazem com que seu estado varie ao longo do tempo, dos quais o ciclo menstrual nas mulheres é um exemplo, o ritmo circadiano que manifesta nossos estados funcionais ao longo do dia, outro; cada pessoa manifesta os efeitos do envelhecimento de maneira diferente, mesmo que tenha experienciado situações semelhantes etc.). A esse respeito, conferir Guérin et al. (2004). 
conjunto de escolhas, isso no sentido de tomada de decisões e eleição de prioridades. Por conseguinte, as formas de proceder guardam uma imagem de organização do trabalho, de homem, de desempenho, de produtividade etc. Enfim, as formas de proceder portam uma maneira de ver e de fazer. Nesse horizonte, se a realidade se constitui de uma totalidade, a gestão implica o exercício de dimensionamento desta, um exercício de redução tendo em vista tornar palpável o que será realizado. “Toda organização procede de uma redução" (Hubault, 2005, p. 1).

Estudioso da gestão, o ergonomista François Hubault assinala o que está em jogo na questão: de um lado, as ferramentas de gestão simplificam a realidade, um efeito direto da redução; de outro, é preciso pôr o problema do que elas deixam escapar.

Organizar o trabalho é forçosamente dimensionar os recursos - cognitivos, materiais, sociais - que lhe são alocados, os postos que lhe são confiados, nos quais são jogados os compromissos que lhes são exigidos, em razão dos riscos que se está incumbido de conter em um cenário de criação de valor que justifica seu papel. Mas, assim fazendo, o trabalho herda dentro do mesmo movimento a responsabilidade de fazer face também a tudo o que a organização não regula e de conter também o que pode surgir dos flancos não defendidos ou menos resguardados [moins pourvus]. Tudo depende então da maneira cujo trabalho ainda consegue êxito, contendo o que transborda [ao delineado pela gestão]. (idem, ibidem)

Hubault destaca que, no âmbito de uma organização, a gestão delineia suas ações e que, de outra parte, o trabalho é algo que transborda o enquadramento por ela efetuado. Para entender isso, é preciso recordar a proposição fundadora da ergonomia: o trabalho prescrito não coincide com o trabalho real. Em outros termos, a dinâmica das situações de trabalho e sua complexidade não permitem uma linha reta entre as consignas prévias e o efetivamente realizado; quem faz esse movimento do prescrito ao real é a atividade do trabalhador.

Com base nessa perspectiva, podemos dizer que a gestão não é prerrogativa dos que estão na condição de diretores do processo, mas que o próprio trabalhador também a realiza. Atento a isso, na sequência, Hubault sublinha o lugar do trabalhador em um processo no qual a gestão simplifica o complexo e os trabalhadores - e é por isso que a produção "sai" - recompõem o perímetro na realização do trabalho. Duplo movimento de uma tensão ineliminável, que não pode ser suprimida, mas trabalhada.

Em suma, se uma organização se vale sempre de uma solução para fazer frente às ameaças com as quais confronta sua atividade, ela é, ao mesmo tempo, uma experiência na qual os operadores põem à prova [éprouvent] os limites dessa solução. O que lhes faz saber que essa solução é para eles um problema. Podemos dizer que, escolhendo os riscos dos quais ela decide se proteger, a organização designa, ao mesmo tempo, o que ela desloca no espaço não regulado do trabalho 
real [...]. Para a ergonomia, essa é a questão em jogo [l'enjeu] no conceito de situação de trabalho: fazer reconhecer que o perímetro real da atividade real não se limita jamais ao perímetro do posto [...], o trabalho não se pode restringir aos limites espaço-temporais do posto, nem dos recursos que lhes são atribuídos. $\mathrm{O}$ trabalho pode finalmente ser definido como o encarregado do que transborda do enquadramento gestionário [cadrage gestionnaire]; sublinhada assim, a atividade se deve principalmente à consideração daqueles que são deixados de lado. A tensão é então ineliminável entre o movimento de homogeneização, simplificação, concentração da gestão sobre as dimensões que lhes são mais sensíveis, e o movimento de recomposição do perímetro da tomada do real pelo trabalho. (Hubault, 2005, p. 2)

Enfim, quando tomamos o trabalho a partir de baixo, confrontamo-nos com esferas essenciais em sua realização, mas seria preciso indagar se a gestão possui disposição para transitar por tais esferas e interesse de fazê-lo. Ignorá-las pode conduzir a contradições graves - e já vimos algumas delas ao longo do presente texto -, mas isso não parece ser razão suficiente para uma mudança de perspectiva dos gestores no alto do sistema; por isso, a tarefa dos interessados em outro modo de conceber e de realizar o trabalho não é somente uma tarefa técnica - no sentido de que o trabalho concreto não é diretamente visível, demandando ele mesmo um trabalho para tal-, mas também uma tarefa política.

Nas linhas de funcionamento ordinário de uma empresa ou de uma instituição, o trabalho é, para a gestão, reduzido a fator ou fator de produção. No entanto, efetivamente, o "trabalho não é um fator como os outros: ele atravessa todos os níveis, religa todos os fatores, o que tende a subestimar o modo de cálculo da produtividade... do trabalho" (Blazejewski; Hubault, 1999, p. 26). Essa questão, que concerne à tentativa de se apreender a produtividade do trabalho, remete ao próximo problema em tela: o modo como a gestão apreende o que ela precisa gerir.

\section{AVALIAR E GERIR O TRABALHO}

Comecemos por um caso emblemático: já ouviram falar em benchmarking? Ainda que rapidamente, o termo já apareceu nas reflexões anteriormente apresentadas: está na lista de ações propostas pelo Nerw Public Management (Quadro 1). Uma conhecida firma de consultoria, a Bain \& Company, listava-o entre as ferramentas de gestão mais utilizadas por empresas de diversos países (Rigby, 2009). Mas o que exatamente compreende o benchmarking? Trata-se de um mecanismo de avaliação, mais exatamente de uma ferramenta de avaliação comparativa, um escalonamento de desempenhos. Uma "ferramenta de autoavaliação e ajuda na decisão concebida pela ciência gerencial com a preocupação de racionalização organizacional” (Bruno, 2008, p. 29).

A título de ilustração, temos que uma empresa do ramo têxtil coexiste com outras do mesmo ramo e algumas entre elas conseguem realizar a produção de 
maneira diferenciada, são mais eficientes; o benchmarking colocaria em evidência esses desempenhos e destacaria assim as melhores práticas.

Diversas escalas comparativas são possíveis: local, regional, nacional, internacional; mas, seja como for, é comparando e se comparando que o processo ganha movimento; daí, os desempenhos cifrados, as classificações, os rankings. A grandeza competitiva precisa ser materializada e são os números que a consubstanciam. Em um estudo sobre o tema, Bruno (2008) observa que as pessoas em geral podem não ter ouvido falar do benchmarking, mas já se viram certamente diante dele, pois são suas fontes que alimentam a classificação e o ranking de empresas de eletroeletrônicos, bancos, mas também de hospitais, escolas e universidades. Se a disponibilização de dados para a administração vem de longe, ${ }^{13}$ o que é singular no benchmarking é ser um

dispositivo de coordenação que combina um saber-fazer de comensuração, ou seja, estabelece a equivalência e diferenciação possível, com uma engenharia de gestão que atualiza a concorrência como um princípio de associação e a competitividade como finalidade de toda organização. (idem, p. 31)

Para compreendermos a extensão do que foi dito anteriormente, importa sublinhar dois pressupostos dessa tecnologia de governo: primeiramente, uma organização se torna competitiva expondo-se à concorrência; em segundo lugar, se a ciência econômica ensina que o mercado concorrencial é o dispositivo de coordenação mais eficiente, a organização precisa de uma coordenação mais eficiente para ser competitiva no mercado concorrencial; resulta que os managers - respaldados por sua ciência - são os responsáveis pela coordenação das condições de competição interna à organização e da produção de informações que permitam confrontar a performance de seus membros (idem).

A autora mostra como tal lógica pode ter seu ponto de partida localizado nos anos de 1970, com Robert Camp, chefe de projeto no departamento de logística da empresa Rank Xerox, nos Estados Unidos, e ainda que tais movimentos não são lineares, difundem-se para outras empresas privadas e públicas, livros lhes são consagrados e diversas instituições, como a Organização para a Cooperação e Desenvolvimento Econômico (OCDE), esposam seus ideários e práticas.

Os neoliberais dos anos de 1970 também encontraram o benchmarking. Por isso, no quadro do que Bruno chama de modernidade gestionária, o New Public Management lhe fez eco. Em síntese, a clivagem entre gestão da empresa privada e da gestão pública foi ultrapassada.

$\mathrm{E}$ por que relatar tudo isso? Porque parece ser um pertinente exemplo das formas de proceder habituais da gestão no que se refere aos usos da avaliação e

13 A própria história da estatística, em sua constituição como ciência do Estado, testemunha-o: era preciso "conhecer as populações, trazidas do distante através das estatísticas, as quais se tornavam pensáveis e conhecidas, de sorte que era possível governá-las" (Traversini; Bello, 2009, p. 141). 
também de seus pontos cegos no tocante ao trabalho. Como vimos, todo um esforço metodológico é posto em marcha pelos managers com o objetivo de conhecer o que se passa; todavia, a dinâmica do trabalho concreto não aparece.

$\mathrm{O}$ que fazem os homens e mulheres no trabalho é tido primeiro como uma evidência, em seguida como algo delimitado e colhido em exterioridade às situações concretas, pois seu conteúdo (condensado em índices de produtividade, índices de desempenho etc.) estaria disponível ao interesse instrumental da gestão. Em resumo, separa-se o homem da atividade e esta é, de certo modo, apagada. ${ }^{14}$ Nesse ponto - destaque importante -, o problema deixa de ser próprio ao benchmarking e encontra a tensão que mais amplamente atravessa a relação entre gestão e trabalho.

Ao estudar os atuais sistemas de avaliação do trabalho, Dujarier (2010) observa que há neles a hipótese implícita de que é possível dar um valor para o trabalho sem levar em consideração o contexto ou a tarefa. Vale sublinhar que não é por outro motivo que aqueles que, por ofício, frequentam habitualmente as escolas escutam dos professores que as avaliações realizadas pelas secretarias de educação não têm grande relação com o que eles fazem realmente. Isso retoma uma conhecida divisão na organização do trabalho.

Assim, para Dujarier (2010), os sistemas contemporâneos que se propõem a efetuar a avaliação do trabalho por outras vias realizam o projeto tayloriano ao desenharem um percurso que tenciona separar o pensamento e a ação no que se refere à realização do trabalho. Ao fim das contas, "reencontramos de um lado os engenheiros e managers que pensam os procedimentos de julgamento do trabalho sem o fazer. Do outro, os trabalhadores cujo julgamento no curso da atividade tem menos legitimidade que os critérios de avaliação formais" (Dujarier, 2010, p. 143).

Ora, se tudo o que foi dito anteriormente faz sentido, são as próprias bases da relação entre gestão e trabalho que estão em xeque. A dinâmica das situações de trabalho e a complexidade da atividade humana desaparecem, ao passo que a gestão ensaia pilotar o sistema pelo lado de fora. Mas, se é assim, aquilo que é a substância mesma sobre a qual incide a gestão resta largamente incompreendida.

Um tanto ironicamente, Marc Bartoli (2009) perguntava a um grupo de especialistas em relação às práticas da gestão: o que é que nós gerimos verdadeiramente? Aqui, ao chegarmos a esse ponto, os leitores e leitoras podem ter uma boa noção de como a avaliação do desempenho docente proposta pelos neogestores não é outra coisa que oca; talvez pudéssemos igualmente indagá-los: em meio à profusão de indicadores de performance e à busca por cumprimento de metas, o que os senhores estão gerindo verdadeiramente?

14 Yves Schwartz vem sublinhando esse aspecto, destacando como o sistema de gestão por resultados arrisca obscurecer a dimensão da atividade, o que pode resultar em contradições graves. Conferir, por exemplo, Schwartz e Durrive (2007). 


\section{APÓS FAZERMOS ESSE PERCURSO, O QUE CONCLUIR?}

O que dizer das ambições da gestão diante do trabalho humano? Inerente à relação salarial, portanto ao conflito entre trabalho e capital, o governo do trabalho compõe o fundo sobre o qual se movimentam antigos e atuais modelos de gestão. Todavia, o encontro com o trabalho vivo não raro surpreende os que, estando de fora, desejam anexá-lo; de um lado, porque, seguindo Canguilhem, pode-se dizer que o trabalho vivo é vivo e, ${ }^{15}$ de outro, porque a condução dos processos de gestão não tem na devida conta a complexidade das situações de trabalho, obscurecendo justamente o que lhes é basilar: a atividade humana de trabalho.

Hubault (2005) vai direto ao ponto: as organizações têm uma relação maldita com o cotidiano. Este é o lugar, diz o referido autor, em que o manager está entregue a si mesmo; premido entre a postura do é assim que deve ser feito e a fuga para frente no universo do o que será, ele tem dificuldade de compreender o que se passa. Os gestores parecem lidar mal com as situações de trabalho. Essa é uma realidade demasiadamente complexa, da qual a saída para eles tem sido a simplificação; assim, no precipitar de um sem-número de decisões e ações, esse ativismo gestionário tem cada vez mais dificuldade de mascarar a indigência da gestão diante do trabalho humano (Blazejewski; Hubault, 1999).

Seria possível fazer de outro modo? Sim, seria. Mas isso envolveria, pelo menos, em primeiro lugar, ir além do restrito horizonte do homo ceconomicus - produção de um mundo objetivo, o trabalho é também ocasião de uma realização subjetiva (Hubault, 1999), é uma base que mantém o sujeito no homem (Clot, 2009), e nele o trabalhador se coloca, tenta dar sentido ao que faz, mobiliza seu corpo e põe em jogo sua saúde (Davezies, 2010); o trabalho é impossível de ser completamente antecipado (isto é, definido estritamente por normas antecedentes), antes que as pessoas atuem, o trabalho exige sempre (mesmo que de maneira pouco visível) algo de uma reinvenção local (isto é, renormalizaçôes), esfera de algo enigmático: a atividade humana (Schwartz; Durrive, 2007).

Em segundo lugar, envolveria conhecer o debate que vem se formando em torno da complexidade do trabalho humano, da dinâmica do mundo do trabalho contemporâneo e das exigências que este traz para a gestão, cujas referências podem ser encontradas em estudiosos de diversas áreas, da economia à filosofia. ${ }^{16}$

15 O médico-filósofo francês Georges Canguilhem desenvolveu uma filosofia de vida bastante original que influenciou diversos estudiosos da relação entre trabalho e saúde. Canguilhem evidencia como aquilo que é vivo não é indiferente ao meio (a indiferença é a própria ausência da vida), bem como que a vida comporta normatividade, isto é, capacidade de ser normativo em relação ao meio (perda da capacidade normativa assinala justamente o patológico). Assim, de modo um tanto esquemático, podemos dizer que a vida resiste à sua anexação de fora ao mesmo tempo em que o debate com o meio é algo sempre aberto: a vida joga contra a entropia crescente, diz o referido autor. Conferir Canguilhem (2006, 2009).

16 Ver, por exemplo, Blazejewski e Hubault (1999); Gadrey (2007); Schwartz e Durrive (2007); Zarifian (2009). 
Certamente, a passagem por esses autores colidiria com muitas crenças arraigadas sobre a matéria e, evidentemente, traria desconforto às colegiais certezas que embalam nossos neogestores da educação que, munidos de suas ferramentas de controle e incitação, ensaiam mudar os rumos das escolas.

Essas ferramentas de gestão guardam implícita a ideia de que o problema está do lado das pessoas - do lado dos professores, mais exatamente -, e é compreensível que não seja agradável aos gestores se verem diante de impertinentes colocações, como a que fazia o ergonomista Jacques Duraffourg na ocasião de um diálogo no qual dizia que era preciso evitar as falsas questões no que se refere à relação entre trabalho e gestão. De maneira simples e direta, Duraffourg (2007) lembrava a seu interlocutor que as pessoas são perfeitamente capazes, desde que lhes sejam oferecidas as condições, e perguntava-lhe de maneira desconcertante: "você conhece pessoas que têm o prazer de trabalhar de maneira ineficaz?"

Se conseguirmos tirar consequências de observações tão modestas como essas, então, quem sabe, poderíamos colocar o trabalho, suas condições e seus conteúdos no centro das preocupações e assim as questões fundamentais poderiam começar a ser efetivamente enfrentadas. De todo modo, com o que temos até agora no âmbito das políticas e da gestão educacional, a competência humana no trabalho continua longe de ser abordada como "síntese de ingredientes complexos" (Schwartz, 1998). Como esta se produz e se desenvolve resta largamente incompreendido.

\section{CONSIDERAÇÕES FINAIS}

No presente texto, buscamos problematizar as ambições da gestão em relação ao trabalho, destacando especialmente algumas das iniciativas interessadas em dimensioná-lo e governá-lo, das quais o caso da rede estadual de ensino paulista foi o ponto de partida. Com base em evidências empíricas, no texto argumentamos que as ações da gestão nem sempre são exitosas como deixa transparecer sua aura técnica e modernizadora. Argumentamos que o trabalho é objeto complexo e que, para lidar com ele, as ferramentas de gestão o simplificam e o reduzem, o que não resta sem consequências, seja por vezes comprometendo o projeto da empresa ou instituição, seja desperdiçando a competência humana, seja arriscando a degradar as situações laborais e a própria saúde dos trabalhadores.

Argumentamos que as iniciativas que ambicionam dimensionar o trabalho, ao buscarem torná-lo disponível à gestão - por meio de metas, índices, números etc. - , constituem um horizonte no qual o conteúdo concreto do trabalho fica cada vez mais distante, questão grave quando se considera o lugar da atividade do trabalhador na relação não linear existente entre trabalho prescrito e trabalho real. Argumentamos também que o resultante de tudo isso é que as modernas formas de gestão incidem sobre situações de trabalho nas quais arriscam perder a própria substância do que se propõem gerir; paradoxalmente, conhece-se o trabalho e este permanece um continente largamente desconhecido. 
Há assuntos importantes ligados diretamente à matéria que não foram tratados no texto. Caberia, por exemplo, uma reflexão sobre a proximidade entre as atuais práticas gestionárias na educação e o essencial do projeto taylorista: o sonho da fusão entre trabalho prescrito e trabalho real - uma loucura racional, como tão bem o definiu Bernard Doray. ${ }^{17}$ Caberia igualmente uma reflexão sobre gestão e trabalho que tivesse ao fundo algo que, ao que tudo indica, será cada vez mais presente na área da educação: as firmas de consultoria no apoio à gestão das secretarias de educação. ${ }^{18}$ Mas, como não é possível tratar de tais temas neste espaço, podemos abordá-los em outro momento e deixar as portas abertas para outros pesquisadores. Com as sábias palavras de Miguel Arroyo, ao comentar as novas tendências da gestão da educação, encerramos o presente texto.

O que pensar destas miraculosas medidas? Quando o diagnóstico é superficial, não se acerta com a doença. Curandeiros que vêm de fora, de visita, ao campo tenso e problemático da educação pública, não conseguem enganar aqueles que por anos se defrontam com a gravidade dos crônicos problemas de nossa educação. Que tentam enfrentá-los na precariedade das condições do trabalho docente e discente. Estes neogestores passam rápido, se cansam de aplicar remédios ineficientes. Os milhares de profissionais das escolas públicas tão abandonadas continuarão fazendo o impossível para garantir o direito à educação básica aos filhos e filhas do povo. (Arroyo, 2008, p. 2)

\section{REFERÊNCIAS}

Alves, Wanderson Ferreira. O trabalho dos professores: saberes, valores, atividade. Campinas: Papirus, 2010.

Arroyo, Miguel. Premiar o mérito: a educação no pódio? Revista Época, São Paulo: Globo, 2008. Disponível em: <www.cnte.org.br/.../726-revista-debate-certificacaode-professores>. Acesso em: 10 jan. 2012. [Debate promovido pela Revista Época em 13 de abril de 2008]

Bartoli, Marc. Peut-on gérer les ressources humaines? In: Colloque International: “Travail, identité, mÉtier”. Paris: Collège de France/CNAM, 2009.

17 Fazemos menção à Le taylorisme: une folie rationnelle, obra publicada por Bernard Doray (Paris, Dunod, 1981).

18 O jornal Folha de S. Paulo, edição de 7 de maio de 2011, anunciava que o governo do estado de São Paulo firmava contrato com uma empresa de consultoria norte-americana, a McKinsey, tendo em vista melhorar o ensino de suas escolas. Segundo o jornal, a meta é que São Paulo entre na lista dos 25 melhores sistemas educacionais do mundo até 2030. O secretário da Educação, Herman Voorwald, explica: "Para alcançá-la, a consultoria externa nos dará método, disciplina e acompanhará o andamento das ações”. 
Beauvallet, Maya. Les stratégies absurdes: comment faire pire en croyant faire mieux. Paris: Éditions du Seuil, 2010.

Bezes, Philippe. Le renouveau du contrôle des bureaucraties: l'impact du new public manager. Informations Sociales, Paris: CNAF, v. 6, n. 126, p. 26-37, 2005.

Blazejewski, Frédéric; Hubault, François. De la gestion comme contexte, à la gestion comme domaine d'intervention. In: Congrès de la Sociétè D'Ergonomie de Langue Française, 34., 1999. Caen, France. Actes... Caen: ARACT Haute Normandie Rouen, 15-17 sept. 1999.

Bruno, Isabelle. La recherche scientifique au crible du benchmarking. Petit histoire d'une technologie de gouvernement. Revue d'Histoire Moderne et Contemporaine, Paris: Belin, n. 55-4 bis, p. 28-45, 2008.

Canguilhem, Georges. O normal e o patológico. 6. ed. Rio de Janeiro: Forense, 2006.

. La connaissance de la vie. 10. ed. Paris: Vrin, 2009.

Clot, Yves. A função psicológica do trabalho. Petrópolis: Vozes, 2009.

Le travail à coeur. Paris: La Découvert, 2010.

;Zarifian, Philippe. Evaluation des performances, point aveugle. Le Monde, Paris, 19 déc. 2009. Disponível em: <http://www.lemonde.fr/idees/article/2009/12/18/evaluationdes-performances-point-aveugle-par-yves-clot-et-philippe-zarifian_1282672_3232. html>. Acesso em: dez. 2013.

Daniellou, François. A ergonomia em busca de seus princípios: debates epistemológicos. São Paulo: Edgard Blücher, 2004.

Les mondes du travail. In: Thèry, Laurence (Dir.). Le travail intenable: resistir collectivement à l'intensification du travail. Paris: La Découvert, 2010.

DAvezies, Philippe. Une affaire personnel? In: Thèry, Laurence (Dir.). Le travail intenable: resistir collectivement à l'intensification du travail. Paris: La Découvert, 2010. Dejellal, Faridah; Gallouj, Faïz. Les services publics à l'épreuve de la productivité et la productivité à l'épreuve des services publics. Revue d'Économie Industrielle, Valbonne, França: Éditions De Boeck Supérieur, n. 119/3, p. 25-54, 2007.

Dugué, Bernard. La folie du changement. In: Thèry, Laurence (Dir.). Le travail intenable: resistir collectivement à l'intensification du travail. Paris: La Découvert, 2010. Dujarier, Marie-Anne. L'automatisation du jugement sur le travail. Mesurer n'est pas évaluer. Cabiers Internationaux de Sociologie, Paris: Presses Universitaires de France, n. 128-129, p. 135-160, 2010.

Duraffourg, Jacques. O trabalho e o ponto de vista da atividade. In: Schwartz, Yves; Durrive, Louis. Trabalho E' ergologia: conversas sobre a atividade humana. Rio de Janeiro: Editora da UFF, 2007.

Fernandes, Maria José da Silva. As recentes reformas educacionais paulistas na visão dos professores. Educação em Revista, Belo Horizonte: UFMG, v. 26, n. 3, p. 75-102, dez. 2010. 
GADREY, Jean. Moins de fonctionnaires, mais plus productifs? Une édifiante étude de cas à La Poste. Alternatives Économiques, Paris, article paru dans l'édition du 15 oct. 2007. Disponível em: <http://www.alternatives-economiques.fr/\&prev=/search\%3 Fq\%3DAlternatives\%2B\%25C3\%2589conomiques\%26biw\%3D1440\%26bih\%3D799>. Acesso em: 12 dez. 2013.

Guérin, François; Laville, Antoine; Daniellou, François; Duraffourg, Jacques; Kerguelem, Alain. Compreender o trabalho para transformá-lo: a prática da ergonomia. São Paulo: Edgard Blücher, 2004.

Hubault, François. Ergonomie et GRH, quelle convergence pour changer la condition du travail? In: Coloques Dares-Aract "Approches Économiques de la prévention DES RISQUES PROFISSIONNELS”. Paris, 2 déc. 2005.

L'approche ergonomique des questions de santé/travail. Revue Mouvements, Paris: La Découverte, n. 58/2, p. 1- 6, 2009.

Minnoto, Maria Angélica Pedra; Penna, Marieta Gouvêa de Oliveira. Valorização do magistério ou darwinismo profissional? Ensaio: Avaliação e Políticas Públicas em Educação, Rio de Janeiro: Fundação Cesgranrio, v. 19, n. 70, p. 149-164, jan./mar. 2011. Mons, Nathalie. Effets théoriques et réels des politiques d'évaluation standardisée. Revue Française de Pedagogie, Paris: INRP, n. 169, p. 99-140, oct./déc. 2009.

Normand, Romuald. Lécole efficace ou l'horizon du monde comme laboratoire. Revue Française de Pedagogie, Paris: INRP, n. 154, p. 33-43, jan./mar. 2006.

Pacheco, Regina Silva. Reformando a administração pública no Brasil: eficiência e accountability democrática. In: Seminário "A Reforma da Administração Pública: possibilidAdes e obstáculos”. Fundação Joaquim Nabuco, Recife, 20-21 ago. 1998.

Rigby, Darrell. Ferramentas de gestão: um guia para executivos. São Paulo: Bain \& Company, 2009.

São Paulo. Lei complementar n. 1.078, de 17 de dezembro de 2008. Institui Bonificação por Resultados (BR), no âmbito da Secretaria da Educação, e dá providências correlatas. Diário Oficial do Estado de São Paulo, Seção I, p. 1, 18 dez. 2008.

. Lei complementar n. 1.097, de 27 de outubro de 2009. Institui o sistema de promoção para os integrantes do Quadro do Magistério da Secretaria da Educação e dá outras providências. Diário Oficial do Estado de São Paulo, Seção I, p. 1, 28 out. 2009.

. Decreto n. 55.217, de 21 de dezembro de 2009. Regulamenta a lei complementar n.1.097, de 2009, que institui o sistema de promoção para os integrantes do Quadro do Magistério da Secretaria da Educação e dá outras providências. Diário Oficial do Estado de São Paulo, Seção I, p. 6, 22 de dez. 2009.

Schwartz, Yves. Os ingredientes da competência: um exercício necessário para uma questão insolúvel. Educação छ Sociedade, Campinas: CEDES, v. 19, n. 65, p. 101-140, dez. 1998.

. Travail et gestion: niveaux, critères, instances. In: . Le paradigme ergologique ou um métier de philosophe. Toulouse: Octarès Éditions, 2000. 
; Durrive, Louis (Orgs.). Trabalho E ergologia: conversas sobre a atividade humana. Rio de Janeiro: Editora da Universidade Federal Fluminense, 2007.

Souza, Aparecida Neri de. Racionalidade econômica e a política educacional em São Paulo. In: Reunião Anual da ANPEd, 23., 2000, Caxambu. Anais... Caxambu: Associação Nacional de Pesquisa e Pós-Graduação em Educação, 2000.

THÉRY, Laurence (Dir.). Le travail intenable: resistir collectivement à l'intensification du travail. Paris: La Découvert, 2010.

Traversini, Clarice; Bello, Samuel. O numerável, o mensurável e o audível: estatística como tecnologia para governar. Educą̧ão छ̋ Realidade, Porto Alegre: UFRGS, 44 (2), p. 135-152, maio/ago. 2009.

Zarifian, Philippe. Le travail et la compétence: entre la puissance et contrôle. Paris: PUF, 2009.

\section{SOBRE O AUTOR}

Wanderson Ferreira Alves é doutor em educação pela Universidade de São Paulo (USP). Professor da Universidade Federal de Goiás (UFG). E-mail:wandersonfalves@yahoo.com.br 


\section{WANDERSON FERREIRA ALVES}

\section{Crítica à razão gestionária na educação: o ponto de vista do trabalho}

O objetivo no texto é problematizar as ambições da gestão em relação ao trabalho humano e algumas das iniciativas que, no âmbito da educação escolar, atualmente buscam governá-lo e dimensioná-lo. Trata-se de um estudo de natureza teórica que mobiliza as contribuições de estudos na área da educação e também das disciplinas que têm o trabalho como objeto de estudo, especialmente as contribuições da ergonomia da atividade. Partiremos de uma situação concreta, o caso da rede pública estadual de ensino paulista, refletindo sobre o trânsito das ferramentas de gestão do setor privado para o público e sobre a efetividade de tais ferramentas. Abordaremos ainda as contradições e limites dessas ferramentas de gestão - e que são também as contradições e limites da própria gestão - diante da complexidade do trabalho humano. Concluímos então com uma breve síntese das questões tratadas, apontando a necessidade de se trazer o trabalho, suas condições e seus conteúdos para o centro da discussão.

Palavras-chave: trabalho; gestão da educação; avaliação do trabalho; ergonomia; ergologia.

\section{Critique of the managerial rationale in education: the point view of work}

The objective of this article is to discuss the ambitions of the management of education in relation to human work and some of the initiatives which, in the field of school education, aim to govern and evaluate it. This is a theoretical study which benefits from the contributions of studies in education and the disciplines which have work as an object of study, especially the contributions of the ergonomics of activity. We shall start from a concrete situation, the case of Sao Paulo state education system, reflecting on the transit of management tools from the private to the public sector and on the effectiveness of such tools. We will also examine the contradictions and limits of these management tools - which are also the contradictions and limits of management itself-given the complexity of human work. We will conclude with a brief summary of the issues covered, pointing to the need to bring work, its conditions and contents to the center of discussion.

Keywords: work; education management; assessment of work; ergonomics; ergology. 


\section{Crítica de la razón administrativa en educación: el punto de vista del trabajo}

Elobjetivo de este texto es cuestionar las ambiciones de gestión de la educación en relación con el trabajo humano y algunas de las iniciativas que -em el ámbito de la educación escolartratan de gobernarlo y dimensionarlo. Este es un estudio teórico que utiliza las aportaciones de los estudios en educación y las disciplinas que tienen el trabajo como un objeto de estudio, especialmente las contribuciones de la ergonomía. El articulo se divide en cuatro apartados, distribuidos em la siguiente en la secuencia: un informe de una realidad concreta, el caso de las escuelas públicas de São Paulo, la reflexión sobre la circulación de herramientas de gestión desde el sector privado al sector público, las contradicciones y los limites de dichas herramientas de gestión -y cuáles son las contradicciones y los limites-ante la complejidad del trabajo humano. Se concluye con un breve resumen de los temas, que apunta hacia la necesidad de ubicar el trabajo, sus condiciones y su contenido en el centro de la discusión.

Palabras clave: trabajo; gestión de la educación; evaluación del trabajo; ergonomia; ergología. 